\title{
MOTIVASI BELAJAR BIOLOGI SISWA SMA DITINJAU DARI POLA ASUH ORANGTUA DAN DUKUNGAN SOSIAL TEMAN SEBAYA
}

\author{
Ahmad Afiif, Al-Fatih Bau Makkulau \\ Fakultas Tarbiyah dan Keguruan UIN Alauddin Makassar \\ ahmad.afif@uin-alauddin.ac.id
}

\begin{abstract}
Abstrak
Penelitian ini termasuk penelitian korelasional yang bertujuan untuk mengetahui hubungan antara pola asuh orang tua dan dukungan sosial teman sebaya terhadap motivasi belajar biologi siswa di SMA Negeri 1 Tanete Rilau Kabupaten Barru. Penelitian ini melibatkan tiga variabel yakni variabel bebas adalah pola asuh orang tua dan dukungan sosial teman sebaya sedangkan variabel terikat adalah motivasi belajar. Populasi dalam penelitian ini adalah seluruh siswa kelas XII IPA di SMAN 1 Tanete Rilau yang berjumlah 111 orang. Sedangkan sampelnya berjumlah 56 siswa diambil melalui teknik random sampling. Instrumen yang digunakan dalam penelitian ini adalah skala pola asuh orang tua, skala dukungan sosial teman sebaya, dan skala motivasi belajar. Teknik analisis data yang digunakan yaitu statistik deskriptif serta statistik inferensial. Berdasarkan hasil analisis data menggunakan statistik deskriptif untuk pola asuh orang tua diperoleh nilai rata-rata 97,9 berada dalam kategori sedang dari 56 sampel diperoleh nilai terendah 82 dan tertinggi113, dukungan sosial teman sebaya diperoleh nilai rata-rata 82,4 berada dalam kategori sedang dari 56 sampel diperoleh nilai terendah 64 dan tertinggi102 dan untuk motivasi diperoleh nilai rata-rata 62,6 berada dalam kategori sedang dari 56 sampel diperoleh nilai terendah 34 dan tertinggi 77. Berdasarkan hasil analisis statistik inferensial dengan uji t menunjukkan bahwa nilai thitung > ttabel $(9,308>2,0048)$ maka $\mathrm{H} 0$ ditolak dan Ha diterima. Ini berarti pola asuh orang tua dan dukungan sosial teman sebaya dengan motivasi belajar memiliki hubungan dengan sumbangsi sebesar $46,29 \%$.
\end{abstract}

Kata kunci: Pola Asuh Orangtua, Dukungan Sosial Teman Sebaya,dan Motivasi Belajar.

\begin{abstract}
This study includes correlational research that aims to determine the relationship between parenting and peer social support to motivation to learn biology of students in SMA Negeri 1 Tanete Rilau Barru District. This research involves three variables ie free variable is parenting parenting and peer social support while the dependent variable is learning motivation. The population in this research is all students of class XII IPA at SMAN 1 Tanete Rilau which amounts to 111 people. While the sample amounted to 56 students taken through random sampling technique. The instruments used in this research are parenting parenting scale, peer social support scale, and motivation learning scale. Data analysis techniques used are descriptive statistics and inferential statistics. Based on the results of data analysis using descriptive statistics for parenting parents obtained an average value of 97.9 are in the medium category of 56 samples obtained the lowest value 82 and the highest 113, social support peers obtained average value 82.4 is in the category of being Of 56 samples obtained the lowest value of 64 and the highest102 and for the motivation obtained an average value of 62.6 is in the medium category of 56 samples obtained the lowest value of 34 and the highest 77 . Based on the results of inferential statistical analysis with $t$ test showed that the value of tvalue $>$ ttable $(9,308>2,0048)$ then $\mathrm{HO}$ is rejected and $\mathrm{Ha}$ accepted. This means parenting parenting and peer social support with learning motivation have a relationship with the contribution of $46.29 \%$
\end{abstract}

Keyword: Parenting, Peer Social Support, Learning Motivation

(C) 2016 Universitas Muria Kudus 


\section{PENDAHULUAN}

Pendidikan merupakan kebutuhan manusia yang selalu mengalami perubahan karena adanya perkembangan di segala bidang kehidupan. Pendidikan pada dasarnya merupakan interaksi pendidik (guru) dengan peserta didik (siswa). Interaksi yang dimaksud yaitu saling mempengaruhi antara pendidik dengan peserta didik.

Salah satu unsur penting dalam pendidikan adalah motivasi peserta didik dalam mengikuti proses pembelajaran. Motivasi merupakan dorongan dasar yang menggerakkan seseorang bertingkah laku. Asumsi ini sejalan dengan pendapat Sadirman yang mengatakan bahwa seseorang itu akan mendapat hasil yang diinginkan dalam belajar bila dalam dirinya terdapat keinginan untuk belajar. Ini berarti bahwa motivasi memiliki pengaruh terhadap keberhasilan siswa untuk mencapai hasil yang optimal. Sebaliknya rendahnya motivasi siswa dalam belajar maka akan rendah pula hasil yang dicapai (Sarifan 2009, 9-9).

Motivasi peserta didik dapat dipengaruhi oleh beberapa faktor, diantaranya adalah pola asuh orang tua dan dukungan sosial teman sebaya. Pola asuh orang tua di ibaratkan melalui adanya perhatian dan kehangatan, yaitu orang tua dalam mengasuh dan menjalin hubungan interpersonal dengan anak disadari adanya perhatian, penghargaan dan kasih sayang, kebebasan berinisiatif. Selanjutnya, dorongan sosial teman meliputi berbagai aspek yang berkaitan dengan psikologi sesorang di antaranya yaitu dorongan emosional, bantuan, maupun materi mencakup hal tersebut. Sistem dukungan teman sebaya sangat beragam di seluruh sekolah dan menurut kelompok usia dari para pendukung teman sebaya itu sendiri (Cowie dan Dawn 2009, 78).

Menurut Santrock (2002), motivasi adalah proses yang memberi semangat, arah, dan kegigihan perilaku. Artinya, perilaku yang memiliki motivasi adalah perilaku yang penuh energi, terarah, dan bertahan lama. Dalam kegiatan belajar, maka motivasi dapat dikatakan sebagai keseluruhan daya penggerak di dalam diri siswa yang menimbulkan kegiatan belajar, yang menjamin kelangsungan dari kegiatan belajar dan memberikan arah pada kegiatan belajar, sehingga tujuan yang dikehendaki oleh subjek belajar itu dapat tercapai

Menurut Mussen (1994), mendefinisikan pola asuh orang tua adalah suatu cara yang digunakan orang tua dalam mencoba berbagai strategi untuk mendorong anak-anaknya mencapai tujuan yang diinginkan. Dimana tujuan tersebut antara lain pengetahuan, nilai moral, standar perilaku yang harus dimiliki anak bila dewasa nanti.

Orang tua memang perlu memperhatikan keadaan anaknya dalam mengajarkan dibutuhkan keterampilan berkomunikasi yang baik terhadap anak, karena dengan komunikasi yang baik dan terarah diharapkan pada anak sudah diterima oleh anak. Semua perbuatan dan tingkah laku dari orang tua merupakan contoh yang baik untuk diterapkan pada diri anak dalam kehidupan sehari-harinya (Nasyrah 2007, 34). 
Dukungan sosial merupakan sumber eksternal yang dapat memberikan bantuan individu dalam mengatasi atau menghadapi suatu persoalan. Mungkin itulah sebabnya mengapa dukungan sosial telah banyak mendapat perhatian dalam dasawarsa terakhir meskipun konsep dukungan sosial itu sendiri masih sulit untuk ditetapkan. Beberapa penulis meletakkan dukungan sosial terutama dalam konteks hubungan akrab atau kualitas hubungan (Samet 1994, 349).

Teman sebaya memiliki peranan yang sangat penting dalam kehidupan kelompok siswa saat ini. Banyaknya waktu yang dihabiskan siswa bersama dengan temanya dapat berpengaruh terhadap kehidupannya. oleh karenanya selain dari bentuk pengasuhan orang tua, teman sebaya dalam lingkungan sosial sangat dianggap penting.

Berdasarkan hasil observasi sementara yang dilakukan oleh peneliti pada pertengahan Februari 2014 pada siswa XII IPA di SMA Negeri 1 Tanete Rilau, diperoleh bahwa masih terdapat siswa yang masih menghadapi masalah dalam motivasi belajar. Hal ini ditandai siswa yang terlalu cepat putus asa, tidak bersemangat dan tidak aktif dalam pembelajaran.

Tujuan dari penelitian ini adalah Mengetahui hubungan antara pola asuh orang tua dan dukungan sosial teman sebaya dengan motivasi belajar siswa XII IPA di SMA Negeri 1 Tanete Rilau Kabupaten Barru.

\section{METODE PENELITIAN}

Jenis penelitian dari adalah penelitian korelasional dengan menggunakan pendekatan kuantitatif, dimana penelitian korelasional dimaksudkan untuk menguji hubungan antara variabel.

Lokasi penelitian bertempat di SMA Negeri 1 Tanete Rilau Kabupaten Barru, dengan subjek penelitian kelas XII IPA. Sekolah ini berlokasi di jalan Poros Pekkae Soppeng, Kec. Tanete Rilau Kabupaten Barru. Subjek penelitian siswa kelas XII IPA dengan jumlah siswa sebanyak 111 orang dari 3 kelas Tahun Pelajaran 2014/2015. Peneliti mengambil 50\% dari populasi yang ada sehingga dari 111 mahasiswa maka didapat 56 siswa sebagai sampelnya. Dengan menggunakan teknik Simple Random Sampling.

Dalam penelitian ini menggunakan skala psikologi. Skala yang digunakan dalam penelitian ini ada tiga, yaitu skala pola asuh orang tua, skala dukungan sosial teman sebaya dan skala motivasi belajar. Dimana Skala pola asuh orang tua disusun berdasarkan teori Baumrind, adapun komponennya sebagai berikut skala ini disusun mengungkap tiga macam pola asuh yang diterapkan di dalam keluarga yaitu otoriter, pola asuh demokratis, dan pola asuh permissif yang terdiri dari beberapa indikator kontrol orang tua terhadap anak, kejelasan komunikasi dan tuntutan orang tua. Skala dukungan sosial ini disusun berdasarkan pada teori Sarafino. Skala ini mengungkap empat aspek dukungan sosial teman sebaya, yaitu dukungan 
emosional, dukungan penghargaan, dukungan instrumental, dan dukungan informasi. Skala pengukuran motivasi belajar ini disusun berdasarkan ciri-ciri motivasi yang diungkap oleh Hamzah B Uno, skala ini mengungkap ciri-ciri motivasi belajar meliputi adanya hasrat dan keinginan untuk berhasil, adanya dorongan dan kebutuhan dalam belajar, adanya harapan dan cita-cita masa depan, adanya penghargaan dalam belajar, adanya kegiatan yang menarik dalam belajar, adanya lingkungan belajar yang kondusif yang memungkinkan peserta didik belajar dengan baik.

Tiap skala memiliki ciri-ciri alternative jawaban yang dipisahkan mejadi item favorable dan unfavorable. System penilaian untuk jawaban adalah sangat setuju (SS), setuju (S), tidak setuju (TS), dan sangat tidak setuju (STS).

Pada pernyataan yang bersifat favorable, subjek akan memperoleh nilai 4 jika menjawab sangat setuju (SS), nilai 3 jika menjawab setuju (S), nilai 2 jika menjawab tidak setuju (TS), dan nilai 1 jika menjawab sangat tidak setuju (STS). Sedangkan pernyataan unfavorable subjek akan memperoleh nilai 1 jika menjawab sangat setuju (SS), nilai 2 jika menjawab setuju (S), nilai 3 jika menjawab tidak setuju (TS), dan nilai 4 jika menjawab sangat tidak setuju (STS).

Pengujian validitas dalam penelitian ini menggunakan korelasi product moment yang perhitungannya menggunakan bantuan program SPSS (Statistical Packaged For Social Science) 20,0 for windows. Metode analisis data yang digunakan dalam penelitian ini adalah analisis korelasi berganda sesuai dengan rumusan masalah, tujuan dan hipotesis dan di anlisis dengan menggunakan bantuan SPSS (Statistical Packaged For Social Science) 20,0 for windows.

\section{HASIL \& PEMBAHASAN}

Hasil penelitian tercermin dari hasil analisis dengan menggunakan uji t, dimana thitung lebih besar dari tabel atau 9,308 > 2,0048, itu berarti HO ditolak. Pada uji prasyarat analisis diperoleh data pola asuh orang tua, dukungan sosial teman sebaya dan motivasi belajar terdistribusi normal karena nilai sig. $>\alpha$ berturut-turut yakni. $(0,648>0,05)(0,714>0,05)$ dan $(0,585>0,05)$ Pada uji linieritas pola asuh orang tua dengan motivasi belajar diperoleh data linier karena nilai sig $>\alpha(0,000<0,05)$. Sedangkan pada uji dukungan sosial teman sebaya dengan motivasi belajar diperoleh data linier karena nilai sig $>\alpha(0,000<0,05)$. Sehingga uji prasyarat normalitas dan linieritas terpenuhi.

Berdasarkan hasil pengujian hipotesis yang memperlihatkan bahwa nilai $t$ yang diperoleh dari hasil perhitungan (thitung) lebih besar daripada nilai t yang diperoleh dari tabel distribusi t (ttabel) dengan taraf signifikansi sebesar $5 \%$ (thitung > ttabel) serta merujuk pada penelitian sebelumnya yang relevan, membuktikan bahwa terdapat hubungan yang signifikan antara pola asuh orang tua dan dukungan sosial teman sebaya dengan motivasi belajar 
biologi siswa XII IPA di SMA Negeri 1 Tanete Rilau Kabupaten Barru sebesar 46,29\% dan sisanya $53,71 \%$ dipengaruhi oleh faktor lain yang tidak sempat diteliti oleh peneliti.

Hasil penelitian ini menunjukkan bahwa terdapat hubungan signifikan yang sedang antara pola asuh orang tua dan dukungan sosial teman sebaya terhadap motivasi belajar siswa XII IPA di SMA Negeri 1 Tanete Rilau Kabupaten Barru. Pola asuh orang tua erat kaitannya dengan pembentukan pribadi anak. Setiap anak perlu diberikan pengasuhan yang baik sejak kecil agar pribadinya dapat terbentuk. Jika pola asuh baik telah timbul dalam diri siswa maka akan timbul pula sikap sosial yang baik, dan otomatis akan meningkatkan motivasi belajar di sekolah.

Motivasi merupakan dorongan dasar yang menggerakkan seseorang bertingkah laku. Dorongan ini berada pada diri seseorang yang menggerakkan untuk melakukan sesuatu yang sesuai dengan dorongan dalam dirinya. Motivasi juga adalah kekuatan, baik dalam diri maupun dari luar yang mendorong seseorang untuk mencapai tujuan tertentu (Hamzah B Uno, 2012).

Motivasi menjadi salah satu faktor yang paling penting dalam proses belajar. Meningkatkan motivasi melahirkan semangat dalam diri siswa untuk dapat memahami pentingnya belajar. Dengan belajar, siswa dapat mengetahui apa yang diketahui dan apa yang tidak diketahui.

Tanpa peran kedua orang tua atau keluarga dan juga dari teman sebaya maka siswa akan mengalami gangguan seperti kurangnya minat, motivasi belajar. Peran pola asuh orang tua juga sangat penting dalam menumbuhkan motivasi belajar siswa, dimana orang tua dapat memberikan pengasuhan, serta fasilitas yang dibutuhkan dan diharapkan dapat pula membimbing untuk dapat memotivasi anak di rumah.

Untuk dapat meningkatkan motivasi diperlukan penggerak untuk dapat mencapainya, karena motivasi bukanlah merupakan bawaan lahir akan tetapi dipelajari dari lingkungan sosial bagi remaja yang terdiri dari keluarga, teman sebaya dan faktor yang lainnya, pihakpihak tersebut merupakan agen yang mengajarkan siswa bias memotivasi dirinya terkhusus pada pembelajaran.

Pada usia remaja, peran teman sebaya memiliki pengaruh besar terhadap kehidupan. Karena dengan teman sebaya ini, siswa dapat lebih terbuka merasa aman dan nyaman sehingga dapat lebih mudah dalam mengeluarkan pendapat yang penting kepada rekannya untuk memberikan dukungan sosial dengan bentuk motivasi.

Sebagaimana yang dikemukakan oleh Thoist mengatakan bahwa dukungan teman sebaya bersumber dari orang-orang yang memiliki hubungan yang berarti bagi individu seperti keluarga teman dekat, rekan kerja, tetangga dan saudara. (Ekasari dan Suhertin, 2012) Lebih lanjut, Budiman mengatakan bahwa keluarga yang di landasi kasih sayang, membuat anak dapat mengembangkan tingkah laku sosial yang baik yang merupakan landasan bagi 
hubungan sosial khususnya dengan teman sebaya (Marini dan Elvi, 2005) hal inilah yang akan menjadikan dirinya termotivasi untuk maju khususnya dalam hal belajar.

\section{SIMPULAN}

\section{Kesimpulan}

Berdasarkan hasil temuan penelitian dan analisis data pada bab sebelumnya maka dapat ditarik kesimpulan sebagai berikut:

1. Gambaran Pola asuh orang tua siswa XII IPA di SMA Negeri 1 Tanete Rilau Kabupaten Barru diperoleh sebanyak 43 orang $(76,8 \%)$ berada dalam kategori sedang, dan 13 orang $(23,2 \%)$ berada dalam kategori tinggi, serta tidak ada seorang pun sampel yang berada dalam kategori randah. Sehingga dapat disimpulkan bahwa siswa XII IPA di SMA Negeri 1 Tanete Rilau Kabupaten Barru memiliki pola asuh orang tua yang sedang.

2. Gambaran dukungan sosial teman sebaya siswa XII IPA di SMA Negeri 1 Tanete Rilau Kabupaten Barru diperoleh sebanyak 1 orang $(1,8 \%)$ berada dalam kategori rendah, dan 48 orang $(85,7 \%)$ berada dalam kategori sedang, serta 7 orang $(12,5 \%)$ berada dalam kategori tinggi. serta tidak ada seorang pun sampel yang berada dalam kategori randah. Sehingga dapat disimpulkan bahwa siswa XII IPA di SMA Negeri 1 Tanete Rilau Kabupaten Barru memiliki dukungan sosial teman sebaya yang sedang.

3. Gambaran dukungan sosial teman sebaya siswa XII IPA di SMA Negeri 1 Tanete Rilau Kabupaten Barru diperoleh sebanyak 1 orang $(1,8 \%)$ berada dalam kategori rendah, dan 48 orang $(85,7 \%)$ berada dalam kategori sedang, serta 7 orang $(12,5 \%)$ berada dalam kategori tinggi. Sehingga dapat disimpulkan bahwa siswa XII IPA di SMA Negeri 1 Tanete Rilau Kabupaten Barru memiliki dukungan sosial teman sebaya yang sedang.

4. Berdasarkan hasil analisis statistik inferensial pola asuh orang tua berpengaruh terhadap motivasi belajar siswa XII IPA di SMA Negeri 1 Tanete Rilau. Sumbangan pengaruh variabel pola asuh orang tua sebesar $30,25 \%$ dan sisanya $69,75 \%$ dipengaruhi oleh variabel lain yang tidak dimasukkan dalam penelitian ini.

5. Berdasarkan hasil analisis statistik inferensial dukungan social teman sebaya berpengaruh terhadap motivasi belajar siswa XII IPA di SMA Negeri 1 Tanete Rilau. Sumbangan pengaruh variabel dukungan social teman sebaya sebesar $40,96 \%$ dan sisanya $59,045 \%$ dipengaruhi oleh variabel lain yang tidak dimasukkan dalam penelitian ini.

6. Berdasarkan hasil analisis statistik inferensial pola asuh orang tua dan dukungan social teman sebaya berpengaruh terhadap motivasi belajar siswa XII IPA di SMA Negeri 1 Tanete Rilau. Sumbangan pengaruh variabel pola asuh orang tua dan 
dukungan sosial teman sebaya sebesar $46,29 \%$ dan sisanya 53,71 dipengaruhi oleh variabel lain yang tidak dimasukkan dalam penelitian ini.

\section{Saran}

Berdasarkan kesimpulan yang telah diuraikan di atas maka dikemukakan saran-saran sebagai implikasi dari hasil penelitian sebagai berikut:

1. Usaha untuk meningkatkan motivasi belajar siswa kelas XII IPA SMA Negeri 1 Tanete

Rilau Kabupaten Barru adalah hendaknya sekolah meningkatkan pelaksanaan pembelajaran di sekolah. Agar motivasi siswa. terhadap belajar sekolah dapat dikembangkan sebagai bentuk motivasi mereka dalam belajar, maka perlu dipahami dan disosialisasikan kepada, warga, sekolah, orang tua dan masyarakat.

2. Diharapkan para guru SMA Negeri 1 Tanate Rilau agar dalam usaha meningkatkan motivasi belajar siswa, sebelum memulai dan mengakhiri kegiatan pembelajaran sebaiknya guru memberikan arahan, bimbingan serta pandangan mengenai perlunya belajar yang baik agar kelak prestasi belajar dari siswa dapat juga bertambah.

3. Diharapkan kepada siswa memahami arti serta manfaat Dukungan sosial teman agar tidak salah dalam bergaul jika di sekolah.

4. Diharapkan orang tua dapat terlibat dalam membimbing dan memberikan pengarahan kepada anak jika tidak di sekolah dalam bentuk usaha, pengawasan serta memberi pengertian kepada, anaknya di rumah.

5. Untuk peneliti selanjutnya, pada penelitian ini, peneliti tidak begitu memperhatikan faktor-faktor lain selain aspek pola asuh orang tua sebagai hal yang dapat memengaruhi pola asuh. Disarankan kepada peneliti selanjutnya dengan topik yang sama agar lebih memperhatikan faktor-faktor tersebut khususnya perbedaan gender, anak ke berapa dalam keluarga dan faktor yang lain. 


\section{DAFTAR PUSTAKA}

B. Samet. (1994). Psikologi Pendidikan. Jakarta: Gramedia.

Cowie, Helen dan Dawn Jennifer. (2009). Penanganan Kekerasan di Sekolah. Jakarta: PT Indeks Macanan Jaya Cemerlang.

Ekasari Agustina dan Suhertin Yuliana. (2012). Kontrol Diri dan Dukungan Teman Sebaya dengan Coping Stress pada Remaja. Jurnal Soul, No 2. Vol 5 September 2012.

John W, Santrock. (2002). Live Span Development, Alih Bahasa: Achmad Chusairi, Perkembangan Masa Hidup, Edisi Kelima, Jilid 1-2. Jakarta: Penerbit Erlangga.

Marini Liza dan Elvi Andriani. (2005). Perbedaan Asertivitas Remaja ditinjau dari Pola Asuh Orangtua. Jurnal Pemikiran dan Penelitian Psikologi, Fakultas Kedokteran USU, No.

2. Vol I September 2005.

Mussen. (1994). Pengembangan dan Keperibadian Anak. Jakarta: Arean.

Nasyrah. (2007). "Korelasi antara pola asuh orang tua dan motivasi belajar siswa kelas XI Man 1 Malang", Skripsi Malang: Fakultas Psikologi. UIN Maulana Malik.

Nurjan, Syarifan, dkk. (2009). Psikologi Belajar. Edisi I, Surabaya: LAPIS-PGMI.

Uno Hamzah B. (2012). Teori Motivasi dan Pengukurannya. Jakarta: Bumi Aksara. 